\title{
APLIKASI PREDIKSI PENJUALAN KENDARAAN BERMOTOR
}

\author{
Ihda Innar Ridho ${ }^{1)}$ \\ ihdaridho@gmail.com \\ Mokhamad Ramdhani Raharjo ${ }^{2)}$ \\ 007.ramdhani@gmail.com \\ Fakultas Teknologi Informasi \\ Universitas Islam Kalimantan Muhammad Arsyad Al Banjari Banjarmasin
}

\begin{abstract}
ABSTRAK
Analisis perencanaan stok penjualan dari item barang yang dijual untuk semua jenis usaha perlu dilakukan, hal tersebut dilakukan untuk memberikan kepuasan terhadap pelanggan karena permintaan konsumen dari barang yang ingin dibeli dengan stok barang yang tersedia sesuai yang diharapkan. Perencaan tersebut juga diperlukan oleh Dealer Resmi Surya Motor Cabang Banjarmasin yang bergerak dibidang penjualan beberapa jenis tipe kendaran merk honda serta jasa service kendaraan. Pentingnya perencanaan stok jumlah kendaraan untuk dijual merupakan langkah yang penting karena kendaran bermotor merk honda banyak diminati oleh masyarakat dan juga banyaknya pesaing usaha lain yang lumayan banyak baik dari dealer resmi yang menjual kendaraan merk lain. Berdasarkan permasalahan tersebut perlu dibuatkan aplikasi perencanaan prediksi stok kendaraan agar masyarakat merasa puas dan tidak membeli ke dealer dan merk lain. Metode yang digunakan untuk memecahkan masalah tersebut dengan membuat aplikasi prediksi dengan menerapkan algoritma Least Square dan Geometrik untuk proses prediksi. Hasil yang didapatkan dengan menggunakan metode Least Square didapatkan hasil prediksi yang sama persis dengan penjualan adalah $58.33 \%$ sedangkan untuk hasil mendekati dengan prediksi penjualan adalah 41,67\% sedangkan dengan metode Geometrik Rasio peningkatan penjualan dengan data uji kendaraan bermotor tipe NEW CBR 150(DPY) perbulan adalah 0,67.
\end{abstract}

Kata Kunci : Prediksi, Stok, Least Square, Geometrik

\section{PENDAHULUAN}

Pada saat ini tingkat penggunaan kendaraan bermotor dari tahun ketahun semakin meningkat, hal tersebut dilihat dari kepadatan arus lalu lintas yang terjadi khususnya di Banjarmasin. Permasalahan yang terjadi disebabkan karena mudahnya masyarakat umum untuk membeli kendaraan bermotor secara kredit ataupun bayar tunai. Berdasarkan data yang dikeluarkan Badan Pusat Statistik (BPS) Wilayah Kalimantan Selatan menginformasikan bawah pertumbuhan kendaraan dari beberapa tahun jumlahnya bertambah. . Pertambahan tersebut tidak dipungkiri dari terdapatnya berapa pelaku usaha yang bergerak dibidang penjualan kendaran bermotor yang menawarkan berbagai jenis merk kendaraan bermotor dengan berbagai teknik promosi untuk menggait dan menarik konsumen atau pembeli yang memerlukannya. Khusus di wilayah Banjarmasin pertumbuhan penggunaan kendaraan bermotor tersebut semakin bertambah, seperti yang ditampilkan pada tabel berikut:

Tabel. 1 Pekermbangan kendaraan Bermotor

\begin{tabular}{cclccc}
\hline No & Tahun & Jumlah & No. & Tahun & Jumlah \\
\hline $\mathbf{1}$ & 1949 & 4584 & $\mathbf{3 4}$ & 1986 & 5118907 \\
$\mathbf{2}$ & 1950 & 5546 & $\mathbf{3 5}$ & 1987 & 5554305 \\
$\mathbf{3}$ & 1951 & 7663 & $\mathbf{3 6}$ & 1988 & 5419531 \\
$\mathbf{4}$ & 1952 & 16468 & $\mathbf{3 7}$ & 1989 & 5722291 \\
$\mathbf{5}$ & 1953 & 21082 & $\mathbf{3 8}$ & 1990 & 6082966 \\
$\mathbf{6}$ & 1954 & 58504 & $\mathbf{3 9}$ & 1991 & 6494871 \\
$\mathbf{7}$ & 1956 & 67194 & $\mathbf{4 0}$ & 1992 & 6941000 \\
$\mathbf{8}$ & 1957 & 99079 & $\mathbf{4 1}$ & 1993 & 7355114 \\
$\mathbf{9}$ & 1958 & 105101 & $\mathbf{4 2}$ & 1994 & 8134903 \\
$\mathbf{1 0}$ & 1959 & 113339 & $\mathbf{4 3}$ & 1995 & 9076831 \\
$\mathbf{1 1}$ & 1963 & 196223 & $\mathbf{4 4}$ & 1996 & 10090805 \\
$\mathbf{1 2}$ & 1964 & 220953 & $\mathbf{4 5}$ & 1997 & 11735797 \\
$\mathbf{1 3}$ & 1965 & 225413 & $\mathbf{4 6}$ & 1998 & 12628991 \\
\hline
\end{tabular}




\begin{tabular}{llllll}
\hline $\mathbf{1 4}$ & 1966 & 281779 & $\mathbf{4 7}$ & 1999 & 13053148 \\
$\mathbf{1 5}$ & 1967 & 284578 & $\mathbf{4 8}$ & 2000 & 13563017 \\
$\mathbf{1 6}$ & 1968 & 308404 & $\mathbf{4 9}$ & 2001 & 15275073 \\
$\mathbf{1 7}$ & 1969 & 368724 & $\mathbf{5 0}$ & 2002 & 17002130 \\
$\mathbf{1 8}$ & 1970 & 440005 & $\mathbf{5 1}$ & 2003 & 19976376 \\
$\mathbf{1 9}$ & 1971 & 528009 & $\mathbf{5 2}$ & 2004 & 23061021 \\
$\mathbf{2 0}$ & 1972 & 615220 & $\mathbf{5 3}$ & 2005 & 28531831 \\
$\mathbf{2 1}$ & 1973 & 714333 & $\mathbf{5 4}$ & 2006 & 32528758 \\
$\mathbf{2 2}$ & 1974 & 944733 & $\mathbf{5 5}$ & 2007 & 41955128 \\
$\mathbf{2 3}$ & 1975 & 1191771 & $\mathbf{5 6}$ & 2008 & 47683681 \\
$\mathbf{2 4}$ & 1976 & 1419375 & $\mathbf{5 7}$ & 2009 & 52767093 \\
$\mathbf{2 5}$ & 1977 & 1704964 & $\mathbf{5 8}$ & 2010 & 61078188 \\
$\mathbf{2 6}$ & 1978 & 1990250 & $\mathbf{5 9}$ & 2011 & 68839341 \\
$\mathbf{2 7}$ & 1979 & 2274958 & $\mathbf{6 0}$ & 2012 & 76381183 \\
$\mathbf{2 8}$ & 1980 & 2671978 & $\mathbf{6 1}$ & 2013 & 84732652 \\
$\mathbf{2 9}$ & 1981 & 3207499 & $\mathbf{6 2}$ & 2014 & 92976240 \\
$\mathbf{3 0}$ & 1982 & 3764442 & $\mathbf{6 3}$ & 2015 & 98881267 \\
$\mathbf{3 1}$ & 1983 & 4135677 & $\mathbf{6 4}$ & 2016 & 105150082 \\
$\mathbf{3 2}$ & 1984 & 4556095 & & & \\
$\mathbf{3 3}$ & 1985 & 4794517 & & & \\
\hline
\end{tabular}

\section{Sumber : Bps Kota Banjarmasin}

Salah satu pelaku usaha atau perusahaan yang bergerak dipenjualan dan juga jasa service kendaran bermotor dari sekian banyak yang ada di Kota Banjarmasin adalah Dealer Surya Motor Cabang Banjarmasin. Surya Motor Banjarmasin merupakan cabang Dealer Penjualan Motor HONDA terbesar di Kalimantan Selatan yang tidak lepas dari perencanaan dan pengelolaan data penjualan sesuai dengan minat pasar. Mengingat pada saat ini semakin ketat penjualan karena beberapa produsen lain yang bergerak pada bidang yang sama juga mengatur strategi penjualan ditambah lagi krisis global serta beberapa pesaing kecil lainya misal penjualan kendaraan bermotor bekas layak pakai semakin menjamur hal ini akan mengakibatkan penjualan tidak menentu dan membuat perencanaan serta strategi pemasaran sangat penting untuk melakukan penjualan salah satunya melalui peramalan. Keberhasilan suatu perusahaan dicerminkan oleh kemampuan manajemen untuk memanfaatkan peluang secara optimal sehingga dapat menghasilkan penjualan dan laba sesuai dengan yang diharapkan. Berdasarkan permasalahan tersebut diperlukan suatu sistem yang bisa mengelola dan meramalkan stok kendaraan bermotor untuk persediaan penjualan sesuai dengan minat pasar sehingga tidak terjadi kekeliruan atau mubazir dari stok kendaraan bermotor.

\section{METODE PENELITIAN}

Perancangan aplikasi prediksi penjualan kendaraan bermotor pada Suya Motor Cabang Banjarmasin melalui beberapa tahapan seperti berikut:

1. Analisis Data

Pada bagian ini dilakukan proses analisa data penjualan dan target penjualan yang sudah direkam untuk kendaraan bermotor berdasarkan merk dan tahun penjualan guna proses selanjutnya.

2. Penerapan Metode Proyeksi dalam kedo Program

Proses penerapan metode proyeksi yang digunakan ada dua macam, yaitu metode Least Square dan Geometrik.

Pendekatan Statistik Least Square

Untuk mendapatkan hasil prediksi stok atau penjualan kendaraan menggunakan formula :

$\mathrm{Y}^{\prime}=\mathrm{a}+\mathrm{bX}$

Nilai a didapatkan dengan formula :

$\mathrm{a}=\frac{\sum y \text { (Data Penjualan) }}{n \text { (Jumlah Data) }}$

Nilai b didapatkan dengan formula :

$\mathrm{b}=\frac{\sum x y \text { (Prediksi Penjualan) }}{\sum_{x}^{2}}$

Pendekatan Metode Geometrik

Untuk mendapatkan hasil prediksi stok atau penjualan kendaraan menggunakan formula :

$$
\begin{aligned}
& \mathrm{P}_{\mathrm{t}}=\mathrm{P}_{0}(1+\mathrm{r})^{\mathrm{n}} \\
& r=\frac{n\left(\sum x y\right)-\sum x \sum y}{\sqrt{\left(\left(n \cdot \sum x^{2}\right)-\left(\sum x\right)^{2}\right)\left(\left(n \cdot \sum y^{2}\right)-\left(\sum y\right)^{2}\right)}}
\end{aligned}
$$

3. Prediksi 
Pada bagian ini dilakukan uji coba prediksi dari data penjualan dengan program yang sudah dibuat terhadap dua metode Least Square dan Geometrik.

4. Evaluasi

Proses ini melakukan evaluasi dari hasil prediksi.

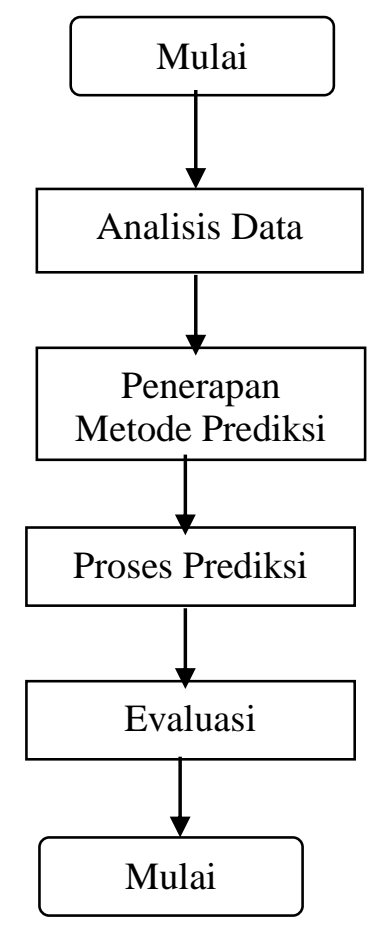

Gambar 1. Alur Pengujian Penelitian

\section{HASIL DAN PEMBAHASAN}

Data yang digunakan untuk pengujian perancangan aplikasi prediksi yaitu menggunakan data penjualan kendaran tipe NEW CBR 150(DPY) yang merupakan kendaraan jenis sport. Data diambil merupakan data penjualan tahun 2015 yang dimulai dari bulan januari sampai desember, serta pada data tersebut terdiri dari dua nilai yaitu, target dan hasil penjualan per bulan yang nantinya data tersebut akan diproses untuk perhitungan prediksi.

Tabel. 2 Data Target Penjulan Tahun 2015

\begin{tabular}{cccc}
\hline No. & Bulan & $\begin{array}{c}\text { Penjualan } \\
(\mathbf{P})\end{array}$ & $\begin{array}{c}\text { Target } \\
\text { Jual }\end{array}$ \\
\hline $\mathbf{1}$ & Januari & 3 & 2 \\
$\mathbf{2}$ & Pebruai & 4 & 3 \\
\hline
\end{tabular}

\begin{tabular}{rlll}
\hline $\mathbf{3}$ & Maret & 4 & 4 \\
$\mathbf{4}$ & April & 4 & 5 \\
$\mathbf{5}$ & Mei & 4 & 5 \\
$\mathbf{6}$ & Juni & 3 & 4 \\
$\mathbf{7}$ & Juli & 1 & 3 \\
$\mathbf{8}$ & Agustus & 2 & 2 \\
$\mathbf{9}$ & September & 1 & 2 \\
$\mathbf{1 0}$ & Oktober & 2 & 2 \\
$\mathbf{1 1}$ & November & 1 & 2 \\
$\mathbf{1 2}$ & Desember & 1 & 2 \\
\hline
\end{tabular}

Pada tahap selanjutnya data akan diuji dengan metode perhitungan Least Square

Tabel.3 Perhitungan Data Least Square

\begin{tabular}{rrrrr}
\hline No. & $\begin{array}{c}\text { Penjualan } \\
(\mathbf{Y})\end{array}$ & $\mathbf{X}$ & $\mathbf{X}^{\mathbf{2}}$ & $\mathbf{X Y}$ \\
\hline $\mathbf{1}$ & 3 & -11 & 121 & -33 \\
$\mathbf{2}$ & 4 & -9 & 81 & -36 \\
$\mathbf{3}$ & 4 & -7 & 49 & -28 \\
$\mathbf{4}$ & 4 & -5 & 25 & -20 \\
$\mathbf{5}$ & 4 & -3 & 9 & -12 \\
$\mathbf{6}$ & 3 & -1 & 1 & -3 \\
$\mathbf{7}$ & 1 & 1 & 1 & 1 \\
$\mathbf{8}$ & 2 & 3 & 9 & 6 \\
$\mathbf{9}$ & 1 & 5 & 25 & 5 \\
$\mathbf{1 0}$ & 2 & 7 & 49 & 14 \\
$\mathbf{1 1}$ & 1 & 9 & 81 & 9 \\
$\mathbf{1 2}$ & 1 & 11 & 121 & 11 \\
\hline
\end{tabular}

1. $\mathrm{n}($ Jumlah Data $)=12$

2. $\sum y($ Penjualan $)=30$

3. $\sum x=0$

4. $\sum X^{2}=572$

5. $\sum X Y=-86$

6. $\mathrm{a}=(30 / 12)=2,5$

7. $\mathrm{b}=(-86 / 572)=-0,15$ 
8. Dari perhitungan beberapa tahapan metode Least Square makan didapatkan model Trend yang gunakan untuk prediksi data selanjutnya sebagai berikut : $\mathrm{Y}^{\prime}=2,5+(-0,15 \mathrm{X})$

Pada tahap berikutnya memasukkan nilai $\mathrm{a}$ dan $\mathrm{b}$ ke dalam rumus $\mathrm{Y}=\mathrm{a}+\mathrm{bX}$ untuk mencari nilai trend value nya.

Tabel 4. Trend Value Peramalan

\begin{tabular}{rll}
\hline No. & \multicolumn{1}{c}{ Bulan } & Trend Value \\
\hline $\mathbf{1}$ & Januari & $=2,5+\left(-0,15^{*}-11\right)=4,15$ \\
$\mathbf{2}$ & Pebruai & $=2,5+\left(-0,15^{*}-9\right)=3,85$ \\
$\mathbf{3}$ & Maret & $=2,5+\left(-0,15^{*}-7\right)=3,55$ \\
$\mathbf{4}$ & April & $=2,5+\left(-0,15^{*}-5\right)=3,25$ \\
$\mathbf{5}$ & Mei & $=2,5+\left(-0,15^{*}-3\right)=3,55$ \\
$\mathbf{6}$ & Juni & $=2,5+\left(-0,15^{*}-1\right)=2,95$ \\
$\mathbf{7}$ & Juli & $=2,5+\left(-0,15^{*} 1\right)=2,35$ \\
$\mathbf{8}$ & Agustus & $=2,5+\left(-0,15^{*} 3\right)=2,05$ \\
$\mathbf{9}$ & September & $=2,5+(-0,15 * 5)=1,75$ \\
$\mathbf{1 0}$ & Oktober & $=2,5+\left(-0,15^{*} 7\right)=3,45$ \\
$\mathbf{1 1}$ & November & $=2,5+\left(-0,15^{*} 9\right)=1,15$ \\
$\mathbf{1 2}$ & Desember & $=2,5+\left(-0,15^{*} 11\right)=0,85$ \\
\hline
\end{tabular}

Pada tahap selanjutnya yaitu membandingkan hasil perhitungan nilai Trend Value terhadap hasil penjualan selama 12 bulan. Perbandingan dengan melihat selisih hasil yang didapatkan apabila selish 1 angka maka keterangan menjadi mendekati jika sama maka keteranganya sama atau mirip antara hasil penjualan dengan nilai prediksi yang dihasilkan.

Tabel 5. Perbandingan Target Penjualan

\begin{tabular}{ccccc}
\hline $\begin{array}{c}\text { No } \\
\boldsymbol{\bullet}\end{array}$ & $\begin{array}{c}\text { Penjuala } \\
\mathbf{n} \\
(\mathbf{P})\end{array}$ & $\begin{array}{c}\text { Targe } \\
\mathbf{t}\end{array}$ & $\begin{array}{c}\text { Target } \\
\text { (Metode } \\
\text { ) }\end{array}$ & Ket. \\
\hline $\mathbf{1}$ & 3 & 2 & 4 & $\begin{array}{c}\text { Mendekat } \\
\mathrm{i}\end{array}$ \\
$\mathbf{2}$ & 4 & 3 & 4 & Sama \\
$\mathbf{3}$ & 4 & 4 & 4 & Sama \\
$\mathbf{4}$ & 4 & 5 & 3 & $\begin{array}{c}\text { Mendekat } \\
\text { i }\end{array}$ \\
$\mathbf{5}$ & 4 & 5 & 4 & Sama \\
\hline
\end{tabular}

\begin{tabular}{|c|c|c|c|c|}
\hline 6 & 3 & 4 & 3 & Sama \\
\hline 7 & 1 & 3 & 2 & $\underset{i}{\text { Mendekat }}$ \\
\hline 8 & 2 & 2 & 2 & Sama \\
\hline 9 & 1 & 2 & 2 & $\begin{array}{c}\text { Mendekat } \\
\text { i }\end{array}$ \\
\hline 10 & 2 & 2 & 3 & $\underset{\mathrm{i}}{\text { Mendekat }}$ \\
\hline 11 & 1 & 2 & 1 & Sama \\
\hline 12 & 1 & 2 & 1 & Sama \\
\hline
\end{tabular}

Untuk pengujian data kedua dengan menggunakan metode Geometrik dalam membuat pola prediksi seperti yang ditampilkan pada tabel dibawah ini :

Tabel 6. Data Perhitungan Geomtrik

\begin{tabular}{rrrrrrrr}
\hline No. & $(\mathbf{P})$ & $\mathbf{X}$ & $\begin{array}{c}\mathbf{Y} \\
\mathbf{I n}(\mathbf{P})\end{array}$ & $\mathbf{X}^{\mathbf{2}}$ & $\mathbf{Y}^{\mathbf{2}}$ & $\mathbf{X Y}$ & $\mathbf{r}$ \\
\hline $\mathbf{1}$ & 3 & 1 & 1,099 & 1 & 1,207 & 1,099 & 0,00 \\
$\mathbf{2}$ & 4 & 2 & 1,386 & 4 & 1,922 & 2,773 & $-0,25$ \\
$\mathbf{3}$ & 4 & 3 & 1,386 & 9 & 1,922 & 4,159 & $-0,25$ \\
$\mathbf{4}$ & 4 & 4 & 1,386 & 16 & 1,922 & 5,545 & $-0,25$ \\
$\mathbf{5}$ & 4 & 5 & 1,386 & 25 & 1,922 & 6,931 & $-0,25$ \\
$\mathbf{6}$ & 3 & 6 & 1,099 & 36 & 1,207 & 6,592 & 0,00 \\
$\mathbf{7}$ & 1 & 7 & 0,000 & 49 & 0,000 & 0,000 & 2,00 \\
$\mathbf{8}$ & 2 & 8 & 0,693 & 64 & 0,480 & 5,545 & 0,50 \\
$\mathbf{9}$ & 1 & 9 & 0,000 & 81 & 0,000 & 0,000 & 2,00 \\
$\mathbf{1 0}$ & 2 & 10 & 0,693 & 100 & 0,480 & 6,931 & 0,50 \\
$\mathbf{1 1}$ & 1 & 11 & 0,000 & 121 & 0,000 & 0,000 & 2,00 \\
$\mathbf{1 2}$ & 1 & 12 & 0,000 & 144 & 0,000 & 0,000 & 2,00 \\
\hline
\end{tabular}

1. $\mathrm{n}($ Jumlah $)=12$

2. $\sum P($ Penjualan $)=30$

3. $\sum X=78$

4. $\sum Y=9,129$

5. $\begin{aligned} \sum X^{2} & =650 \\ \text { 6. } \sum Y^{2} & =11,062\end{aligned}$

7. $\sum X Y=39,575$

8. $\overline{\bar{r}}=0,67$ 
Setelah dilakukan pemodelan data penjualan dengan metode prediksi least Square dan Geomtrik proses selanjutnya dengan pembuatan program aplikasi prediksi seperti hasil dibawah ini :

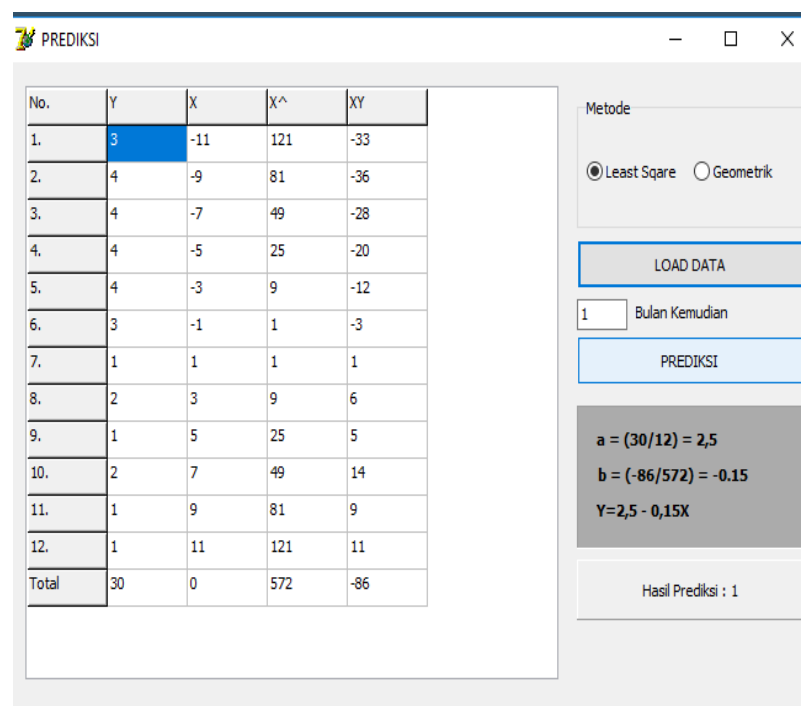

Gambar 2. Hasil Prediksi Metode Least Square

Pada Gambar 2 merupakan implementasi dari hasil penerapan metode perhitungan Least Square untuk mendapatkan hasil prediksi yang akan digunakan berdasarkan model Trend prediksi, uji coba dilakukan dengan memprediksikan 1 bulan kemudian pada Januari 2018 dengan model Trend $\mathrm{Y}^{\prime}=2,5-0,15(13)=0,55=1$. Dari hasil yang didapatkan dapatkan dikatakan bahwa prediksi jenis kendaraan yang laku dijual sebanyak 1 kendaraan untuk jenis NEW CBR 150(DPY).

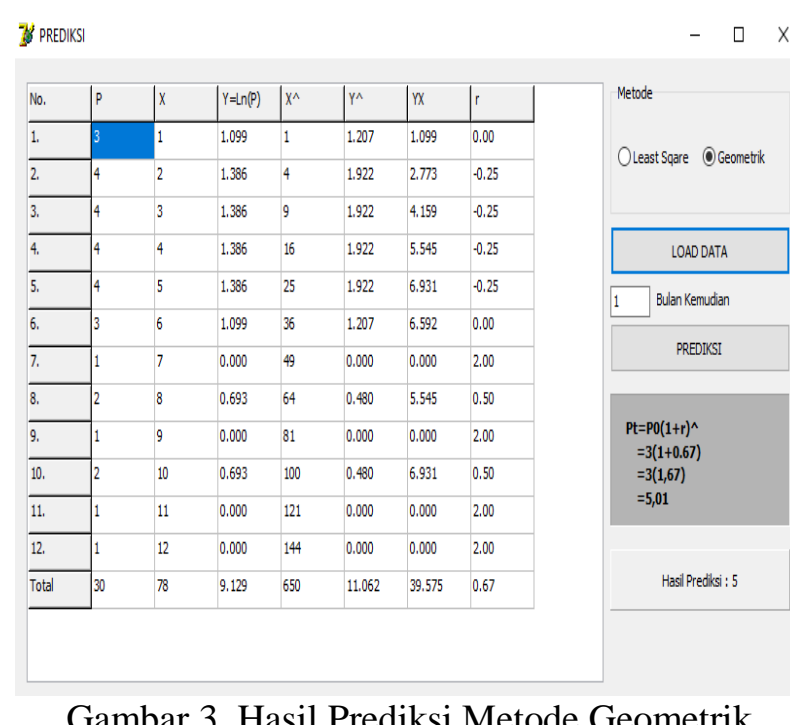

Pada Gambar 3 merupakan implementasi dari hasi penerapan metode perhitungan Geometrik untuk mendapatkan hasil prediksi yang akan digunakan berdasarkan model prediksi yang didapatkan, uji coba dilakukan dengan memprediksikan 1 bulan kemudian pada Januari 2018 dengan model Trend $\mathrm{P}^{\mathrm{t}}=3(1+0,67)^{1}=5,01=5$. Dari hasil yang didapatkan dapatkan dikatakan bahwa prediksi jenis kendaraan yang laku dijual sebanyak 5 kendaraan untuk jenis NEW CBR 150(DPY).

Pada prediksi 1 bulan dengan metode Geometrik menghasilkan nilai $P_{t}=3(1+0,67)^{1}=5,01=5$

\section{KESIMPULAN}

Dari Pembahasan yang dilakukan maka dapat disimpulkan beberapa hal sebagai berikut:

1. Dengan menggunakan metode Least Square didapatkan hasil prediksi yang sama persis dengan penjualan adalah $58.33 \%$ sedangkan untuk hasil mendekati dengan prediksi penjualan adalah $41,67 \%$.

2. Rasio peningkatan penjualan kendaraan bermotor tipe NEW CBR 150(DPY) perbulan dengan metode Geometrik adalah 0,67.

3. Model Prediksi yang terbentuk untuk metode Least Square adalah $\mathrm{Y}^{\prime}=2,5+(-$ $0,15 \mathrm{X})$ dan Geometrik adalah $\mathrm{P}_{\mathrm{t}}=\mathrm{P}_{0}(1+$ $0,67)^{\mathrm{n}}$. 


\section{REFERENSI}

Assauri, S. 1984. Teknik dan Metode Peramalan . Fakultas Ekonomi UI, Jakarta.

Al Fatta, H. (2007). Analisis dan Perancangan Sistem Informasi untuk Keunggulan Bersaing dan Organisasi Modern. Yogyakarta: Andi.

Sukamto, R. A., \& Salahuddin, M. (2011). Modul Pembelajaran Rekayasa Perangkat Lunak. Bandung: Modula.

Banjarmasin, B. k. (2015, April 1). banjarmasinkota.bps.go.id. Retrieved from https://banjarmasinkota.bps.go.i:

https://banjarmasinkota.bps.go.id/ tanggal akses 10 Maret 2018 pukul 13.00 WITA

Basuki. (2011). Analisis Konsumsi Bahan Bakar Pada Pembangkit Listrik Tenaga Uap Dengan Menggunakan Metode Least Square. Undergraduate thesis, Jurusan Teknik Elektro Fakultas Teknik Undip.

Erwin. (2011). Persamaan Metode Least Square. Retrieved from Erwinnote-Antara Kolam Ikan dan Bangku Kuliah: https://erwinnote.wordpress.com

Sarsetyanto, J. (2013). Fungsi Dan Pengertian UML. Retrieved from academia.edu: http://independent.academia.edu

Putra, A. T ., d kk. 2013. Forecas ting of Sheath De mand Us ing Time Se ries Model Autoregress ive Integrated Moving Average and Minimization of Fo recas ting Res ults of The Total Cos t Us ing Wagner - Within. Jurnal Science East Borneo .1:31-39.

Linda, Puspa., Marihat Situmorang., Gim Taringan, "Peramalan Penjualan Produksi Teh Botol Sosro pada PT. Sinar Sosro Sumatera Bagian Urata Tahun 2014 dengan Metode Arima Box Jenkins", Saintia Matematika, vol 02, no. 03 pp. 253-266, 2014

Putra, A. T., dkk. 2013. Forecasting of Sheath De mand Using Time Series Model Autoregress ive Integrated Moving Average and Minimization of Fo recas ting Res ults of The Total Cos $t$ Us ing Wagner - Within. Jurnal Science East Borneo .1:31-39.

Savira, Mia., Nadya N.K Moeliono, "Analisa Peramalan Penjualan Obat Generik Belogo (OGB) pada PT. Indonesia Farma. Fakultas Ekonomi dan Bisnis", Universitas Telkom Bandung, 2014

Paramita, Citra., Dul Muid, "Analisa Perbandingan Metode Peramalan Penjualan Bahan Bakar Minyak dengan Standar Kesalahan Peramalan (SKP) pada PT.
Pertmina (Persero) Region IV Jateng dan DIY”, 2011. 